\title{
Active Living: development and quasi-experimental evaluation of a school-centered physical activity intervention for primary school children
}

Dave H. H. Van Kann ${ }^{1,2^{*}}$, M. W. J. Jansen ${ }^{2,3}$, S. I. de Vries ${ }^{4,5}$, N. K. de Vries ${ }^{1,2}$ and S. P. J. Kremers ${ }^{6}$

\begin{abstract}
Background: The worldwide increase in the rates of childhood overweight and physical inactivity requires successful prevention and intervention programs for children. The aim of the Active Living project is to increase physical activity and decrease sedentary behavior of Dutch primary school children by developing and implementing tailored, multicomponent interventions at and around schools.

Methods/design: In this project, school-centered interventions have been developed at 10 schools in the south of the Netherlands, using a combined top-down and bottom-up approach in which a research unit and a practice unit continuously interact. The interventions consist of a combination of physical and social interventions tailored to local needs of intervention schools. The process and short- and long-term effectiveness of the interventions will be evaluated using a quasi-experimental study design in which 10 intervention schools are matched with 10 control schools. Baseline and follow-up measurements (after 12 and 24 months) have been conducted in grades 6 and 7 and included accelerometry, GPS, and questionnaires. Primary outcome of the Active Living study is the change in physical activity levels, i.e. sedentary behavior (SB), light physical activity (LPA), moderate-to-vigorous physical activity (MVPA), and counts-per-minute (CPM). Multilevel regression analyses will be used to assess the effectiveness of isolated and combined physical and social interventions on children's PA levels.
\end{abstract}

Discussion: The current intervention study is unique in its combined approach of physical and social environmental PA interventions both at school(yard)s as well as in the local neighborhood around the schools. The strength of the study lies in the quasi-experimental design including objective measurement techniques, i.e. accelerometry and GPS, combined with more subjective techniques, i.e. questionnaires, implementation logbooks, and neighborhood observations.

Trial registration: Current Controlled Trials ISRCTN25497687 (registration date 21/10/2015), METC 12-4-077, Project number 200130003

Keywords: Longitudinal evaluation, Quasi-experimental design, Multicomponent interventions, Physical activity, Accelerometry, Primary school environment, Children

\footnotetext{
* Correspondence: d.vankann@maastrichtuniversity.nl

${ }^{1}$ Department of Health Promotion, School of Public Health and Primary Care

(CAPHRI), Maastricht University, P.O. Box 6166200 MD Maastricht, The

Netherlands

${ }^{2}$ Academic Collaborative Center for Public Health Limburg, Public Health

Services, Geleen, The Netherlands

Full list of author information is available at the end of the article
} 


\section{Background}

All over the world, the prevalence of childhood obesity has increased substantially within one generation [1]. As in most developed countries [2], the proportion of overweight and obese children in the Netherlands has tripled between 1980 and 2009, to $16 \%$ [3]. The prevalence of overweight is higher among children with a low socioeconomic (SES) background $[4,5]$. Overweight in children is likely to track into adulthood [6,7], adding to the need for childhood overweight and obesity prevention. The increase in overweight is particularly caused by changed lifestyle behaviors, such as decreased physical activity (PA) and increased sedentary behavior (SB) $[8,9]$, which are nowadays considered two independent risk factors for health, rather than each other's counterparts $[10,11]$. Physical inactivity and sedentary behavior are associated with a wide variety of chronic diseases [12], psychosocial problems [13], and impaired cognitive functioning [14]. Decreased PA and increased SB are likely to be a result of changed environmental factors, such as decreased road safety $[15,16]$ and increased availability of 'screen-based devices' (computers, televisions, tablets etc.) [17].

To date, there have been many interventions that aim to increase children's physical activity levels, especially in the school setting $[18,19]$. Schools are suitable settings for health promotion activities in children in view of their substantial reach [20], which greatly affects the potential impact of an intervention. In addition, the educational system is a learning environment, in which developing a healthy lifestyle could be considered an important objective. Despite these potentials, however, schools are not able to solve the problem of physical inactivity by themselves $[21,22]$. Nonetheless, most school-based PA interventions focus solely on the school setting [23-26], whereas it could be argued that school is only one level of influence [27] and interactions with different ecological levels (e.g. home environment or local neighborhood) are more likely to change health behaviors [28].

The current project focuses on promoting children's PA levels (i.e. active school transportation, PA while attending school, and leisure time PA) in the school setting in a broad sense, including local neighborhoods and parts of the home environment. The Active Living project intends to create PA-friendly school environments by creating a supportive physical environment (e.g. safe routes to school and active schoolyards) accompanied by a supportive social environment (e.g. parental support to walk to school and facilitative teacher practices in schoolyards) (Fig. 1). The interaction between interventions in both types of environments [29] is hypothesized to affect PA and SB favorably [28].

The aim of the Active Living project is to develop and implement tailored, multicomponent schoolcentered PA interventions and test their short- and long-term effectiveness regarding the PA levels of children aged 8-12 years living in deprived areas.

\section{Method \\ Setting and study design}

The current study uses a quasi-experimental design with 10 intervention schools and 10 matched control schools from the Southern-Limburg area in the Netherlands (Fig. 2). It uses a combination of selective and universal prevention. Selective prevention is reflected by the focus on schools in deprived areas [30], with larger proportions of children from lower SES backgrounds. The project is, however, not only designed for low-SES children, but focuses on all children attending the schools in the deprived areas. 'Active Living' is funded by the Netherlands Organization for Health Research and Development (ZonMW), Project Number 200130003 (ISRCTN25497687). Ethical approval was obtained from the research ethics committee of the Maastricht University Medical Centre (reference number METC 12-4-077).

\section{Power calculation}

This project aims to increase children's physical activity levels. More specifically, its target is an increase in the proportion of children meeting the Dutch guideline for physical activity (60 min MVPA daily) from $22 \%$ to $42 \%$ after the project [31, 32]. Interclass variations within the school (0.3) and variations among the schools (0.7) were taken into account in the power calculation. In total, we calculated that 704 children would be needed to obtain sufficient power. In order to achieve this we needed to include 16 schools ( 8 intervention and 8 control schools). Due to potential differences in class sizes and risk of drop-out during the study, the number of schools was increased by $25 \%$ to 20 schools (10 intervention and 10 control schools) and a total of 880 children.

\section{Recruitment of schools and participants}

The Active Living project targets $6^{\text {th }}$-to- $8^{\text {th }}$ grade children (8 to 12 years old) attending primary schools situated in deprived areas in the Southern-Limburg region. In November 2011, municipal development plans of all 19 Southern-Limburg municipalities were checked to see if they contained formal references to the themes of 'youth' and 'overweight prevention'. In total, 12 out of 19 municipalities had formulated targets either for youth or overweight prevention or both. Municipal health officers were visited and informed about the project and conditions for participation. This resulted in six municipalities (31.6\%) wanting to become involved. In these municipalities, four school corporations were identified, three of which agreed to recruit schools falling under their responsibility. To participate in the Active Living project, 


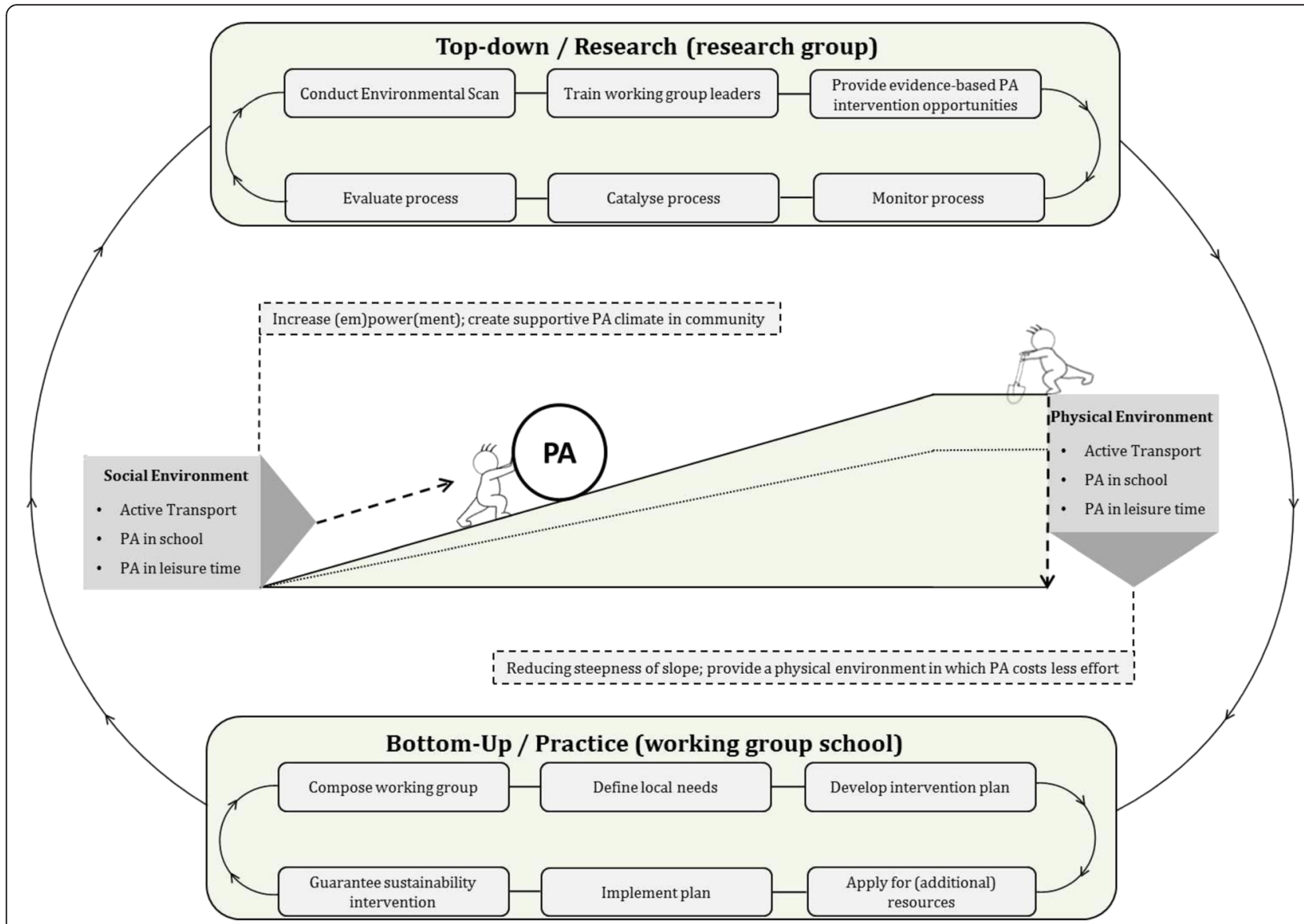

Fig. 1 Active Living development and implementation loop

schools were checked for eligibility according to predefined inclusion criteria: (1) located in a deprived area; (2) at least 25 students enrolled in grades 6 and 7; (3) no plans to merge with another school or plans to relocate in the upcoming 3 years; and (4) willing to actively participate and to form an 'Active Living' working group at school. Within the municipalities and school corporations that consented, 37 primary schools were identified in deprived areas. Municipalities and corporations were asked to recommend schools that were most eligible to participate from their perspective. We visited 13 eligible schools and informed them about the project and conditions for participation; 10 schools $(76.9 \%)$ agreed to participate (Fig. 3). Each of these schools was matched to a control school, taking into account the level of neighborhood deprivation and the level of urbanization (urban vs rural). Ideally, the control school was located in a non-participating municipality, to prevent potential contamination by municipal policy influences. After 10 matching control schools had been recruited, one control school unexpectedly had to relocate to a temporary school building and was thus replaced by an additional control school. In all, therefore, we included 11 control schools, 10 of which were matched to an intervention school. Control schools were only visited during measurements, and no project activities were planned during the intervention period, which comprised two academic years. Control schools were offered Public Health Services (PHS) support to implement effective elements of the project after the end of the effectiveness study.

Before data collection, all participating schools were visited to inform children about the study. Children were able to express their interest in participating in the effect study of the Active Living project. Those children who were interested were provided with written information for their parents. Written informed consent was requested from parents for wearing measurement equipment before and during the project. School principals consented to administer the child questionnaire in the classroom and to ask the parents to fill out the parental questionnaire. After permission was received from the parents to include a child in the study, the child could still refuse further participation in any part of the study without giving any reason. At baseline, parents of 815 children (61.6\%) consented for them to wear the measuring equipment. Figure 4 


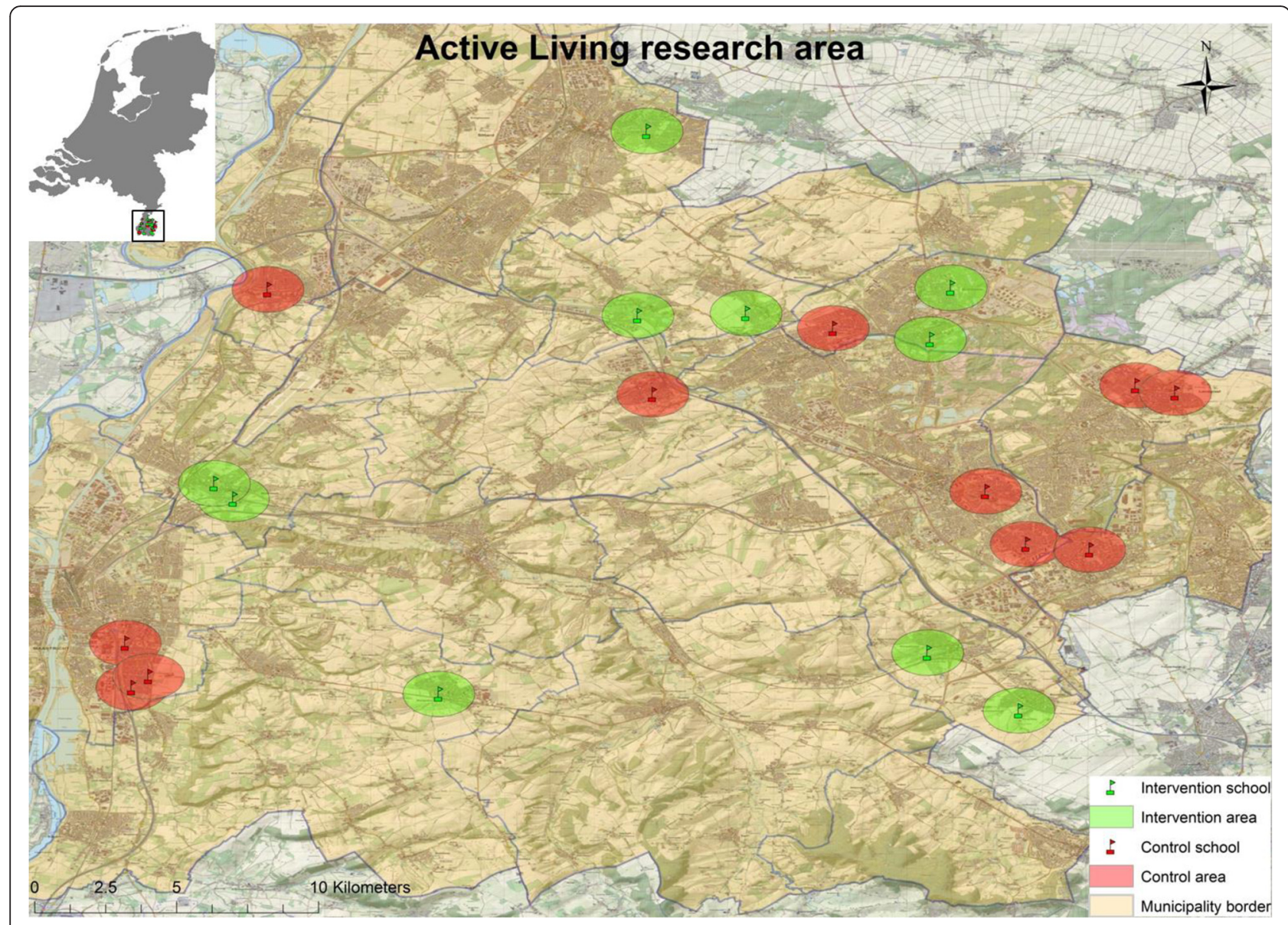

Fig. 2 Active Living research area - Southern-Limburg region, The Netherlands

presents an overview of the participants of the Active Living project.

\section{Data collection}

The baseline measurement (T0) of the Active Living Study was performed between September and December 2012. The first follow-up measurement (T1) was performed 6 months later, between March and June 2013, and a second follow-up (T2) after 18 months, between March and June 2014. To prevent potential seasonal effects, data in each pair of schools (the intervention school and the 'matched' control school) were collected on the exact same dates. Grades 6 and 7 of participating schools were visited by two researchers and a PHS employee at all measurement moments. During classroom visits lasting about $1 \mathrm{~h}$, children were instructed about the procedure of the measurement, were equipped with measurement devices (accelerometer and/or GPS device, see Measures), and individually filled out a questionnaire, which was immediately collected by the researchers. Afterwards, children received a parental questionnaire and were requested to ask their parents to fill it out and return it to school in a supplied envelope. A research assistant visited the schools one week afterwards to collect the measurement equipment and parental questionnaires.

Unexpectedly, the intervention implementation was delayed by at least 6 months as a result of reorganizations at our main executive partner (PHS). As a result, we revised the measurement design of our effectiveness study. The initial T0 measurement was redefined as a pilot and feasibility test (T-1). The measurement in the spring of 2013 was redefined as the baseline measurement (T0) while the original 18-month measurement became the first follow-up in the effectiveness trial ( $\mathrm{T} 1=12$ months). As a result of this, we performed an additional follow-up measurement in the period of March till June 2015 (T2 = 24 months). This will allow us to assess the sustainability of potential effects of the Active Living project on the PA and SB behavior of the children who were in the $6^{\text {th }}$ grade at baseline. Children attending $7^{\text {th }}$ grade at the start of the project made the transition from primary to 


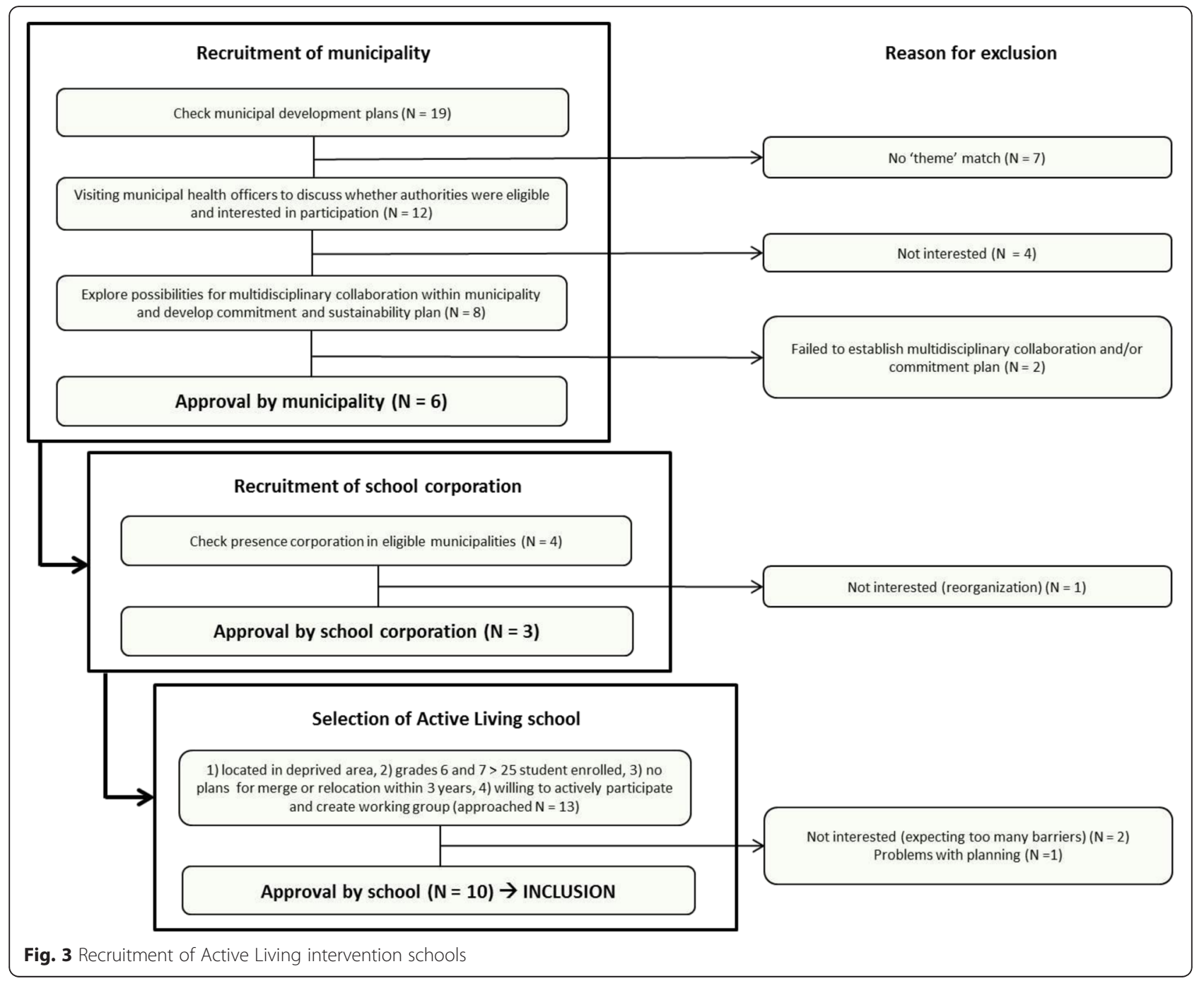

secondary school during the summer of 2014, and were therefore no longer eligible to participate in the additional 24-month measurement (T2).

The revised measurement design led to a loss of power in the study of long-term effects. On the other hand, it increased the comparability between the baseline (T0) and follow-up measurements ( $\mathrm{T} 1$ and $\mathrm{T} 2$ ), since all measurements were now performed in spring (while T-1 was performed in the fall). In addition, a potential novelty effect of wearing measurement devices was prevented by excluding $\mathrm{T}-1$ from the effectiveness trial.

\section{Measures}

\section{Accelerometry and GPS}

PA was measured by waist-worn accelerometers (Actigraph $\mathrm{GT} 3 \mathrm{X}+, 30 \mathrm{~Hz})$. Children were instructed to wear a belt, with the attached accelerometer on their right hip, for at least 5 consecutive days, including a weekend. They were asked to wear the device all day long during waking hours and only remove the belt when performing (substantial) water-involving activities, such as swimming and showering.

At T-1 and at T0, a random selection of children were also asked to wear a GPS device (QStarz BT1000-XT), which was added to their accelerometer belt. We opted for this random approach because of the limited availability of GPS devices. Children additionally wearing a GPS device followed a similar protocol as described for accelerometers, but were asked to charge the device overnight using a supplied adapter. At T1 our GPS capacity was greatly increased, allowing us to ask all children to wear a GPS device in addition to their accelerometer. T2 was designed as an accelerometer-only measurement, to prevent high drop-out rates, as the GPS device was thought to raise the burden of participation for the children.

\section{Child questionnaire}

The child questionnaire included items that can be classified into six main themes (Table 1): demographics; PA 


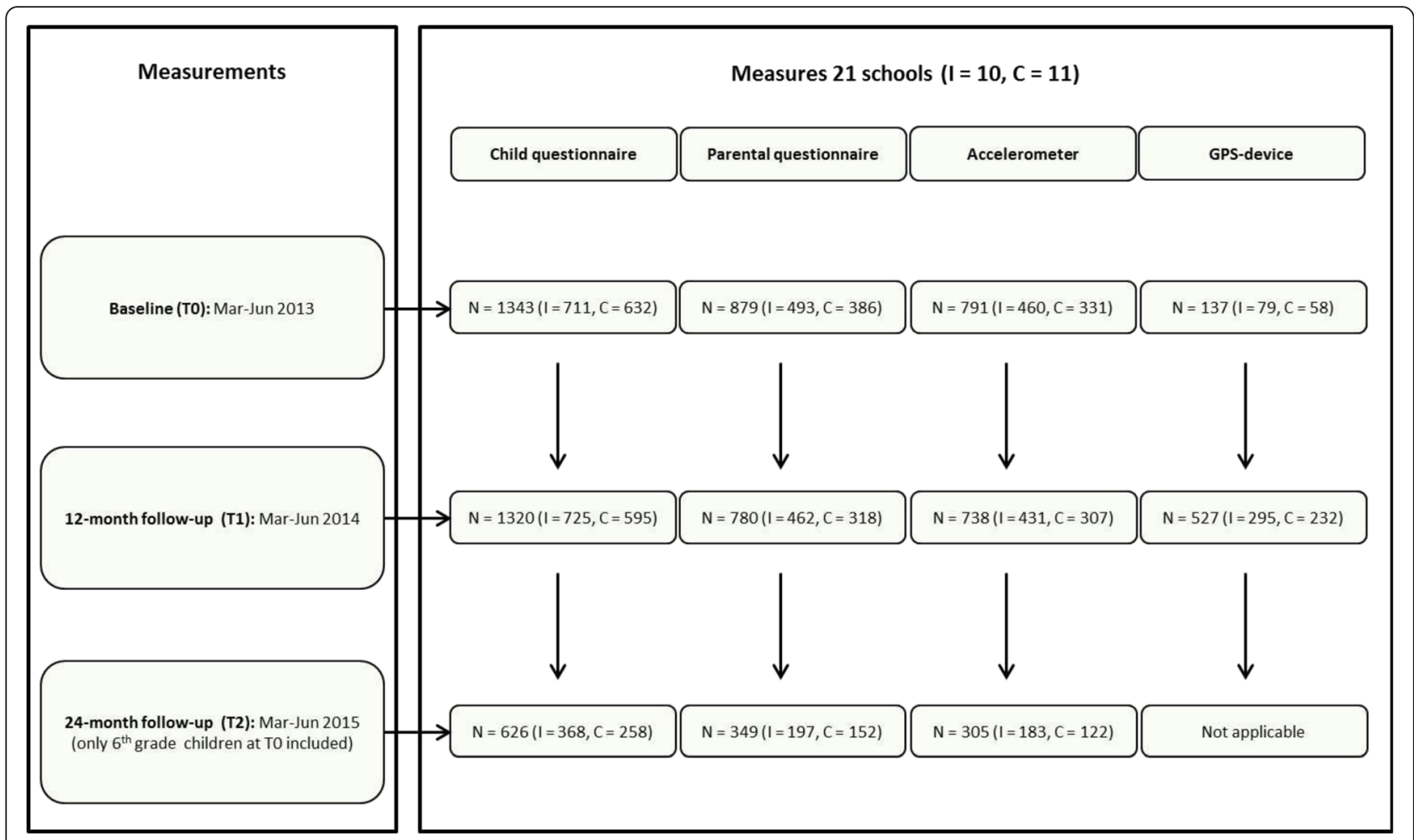

Fig. 4 Overview of participants to the Active Living project

and SB; neighborhood perceptions; rules and practices at home; PA preferences, and impulsivity [33-36]. The questionnaire was pre-tested with children of the target age group to ensure the questions were clear and understandable. The questionnaire was designed to be completed individually by children within approximately $15 \mathrm{~min}$. At

Table 1 Overview of concepts in the child questionnaire

\begin{tabular}{|c|c|c|}
\hline Theme/concept & $\mathrm{N}$ items & Example of items \\
\hline Demographics & 9 & $\begin{array}{l}\text { Gender; Date of birth; Home } \\
\text { address }\end{array}$ \\
\hline Transportation options & 3 & $\begin{array}{l}\text { How did you come to school } \\
\text { this morning? (MC-9) }\end{array}$ \\
\hline PA \& SB & 12 & $\begin{array}{l}\text { On how many days per week } \\
\text { do you play outdoors? (Open) + } \\
\text { duration question }\end{array}$ \\
\hline $\begin{array}{l}\text { Neighborhood } \\
\text { perceptions }\end{array}$ & 7 & $\begin{array}{l}\text { There is heavy traffic in our local } \\
\text { streets (Lik-4) }\end{array}$ \\
\hline $\begin{array}{l}\text { Rules and practices } \\
\text { at home }\end{array}$ & 4 & $\begin{array}{l}\text { At home we have rules about } \\
\text { using the computer or watching } \\
\text { TV (Lik-4) }\end{array}$ \\
\hline PA preferences & 28 & $\begin{array}{l}\text { Visualized comparisons, e.g. outdoor } \\
\text { play vs. reading }\end{array}$ \\
\hline Impulsivity & 13 & I often rush into new things (Lik-5) \\
\hline Process & 4 & $\begin{array}{l}\text { On a scale from } 1-10 \text {, how much } \\
\text { fun do you think Active Living was } \\
\text { to participate in? (SC) }\end{array}$ \\
\hline
\end{tabular}

MC-9 Multiple Choice (9 options), Lik-X X-points Likert Scale, SC Scale
T1, some process evaluation items were added to the questionnaire.

\section{Parental questionnaire}

The parental questionnaire included nine main topics (Table 2): demographics; school transportation choices; neighborhood perceptions; parental PA practices; child's outdoor play; parental active transportation routines (PATRns); rules; biking behavior, and self-reported height and weight of the child, mother, and father [37, 38]. The questionnaire was designed to be completed in $10 \mathrm{~min}$, which was believed to reduce the 'time barrier' to filling out the questionnaire.

\section{Environmental data}

In August 2012, prior to the start of the project at the schools, an environmental scan of all school environments was conducted using the SPACE checklist [39]. This is an adapted version of the Neighborhood Environment Walkability Scale (NEWS) [40], specifically adapted to and validated for the Dutch context. A school environment was defined as an $800 \mathrm{~m}$ crow-fly buffer around every primary school. In 2012, Dutch primary school children lived at an average distance of $600 \mathrm{~m}$ from their nearest primary school [41], so the $800 \mathrm{~m}$ crow-fly buffer seemed appropriate to include both the school and home environment of the primary school 
Table 2 Overview of concepts in the parental questionnaire

\begin{tabular}{|c|c|c|}
\hline Theme/concept & $\mathrm{N}$ items & Example of items \\
\hline Demographics & 11 & Relation to child; Level of education \\
\hline $\begin{array}{l}\text { School transportation } \\
\text { options }\end{array}$ & 3 & $\begin{array}{l}\text { Who accompanies your child during } \\
\text { transportation to school? (MC-6) }\end{array}$ \\
\hline $\begin{array}{l}\text { Neighborhood } \\
\text { perceptions }\end{array}$ & 8 & $\begin{array}{l}\text { Social safety is a concern in our local } \\
\text { neighborhood (Lik-4) }\end{array}$ \\
\hline \multicolumn{3}{|l|}{ Parental PA practices } \\
\hline Modeling & 6 & $\begin{array}{l}\text { How often do you use your own } \\
\text { behavior to encourage your child's } \\
\text { PA? (Lik-5) }\end{array}$ \\
\hline Facilitation & 2 & $\begin{array}{l}\text { How often do you bring your child to } \\
\text { a location where he/she is able to do } \\
\text { sports or be physically active? (Lik-5) }\end{array}$ \\
\hline Social Support & 8 & $\begin{array}{l}\text { How often do you stimulate your } \\
\text { child to be physically active? (Lik-5) }\end{array}$ \\
\hline Child's outdoor play & 10 & $\begin{array}{l}\text { If my child does not play outdoors, it } \\
\text { is because.... there is no playground } \\
\text { in the local neighborhood (Lik-3) }\end{array}$ \\
\hline $\begin{array}{l}\text { Parental Active } \\
\text { Transportation } \\
\text { Routines (PATRns) }\end{array}$ & 4 & $\begin{array}{l}\text { If I have to go somewhere nearby, I } \\
\text { am always inclined to take the bike } \\
\text { or to go on foot (Lik-5) }\end{array}$ \\
\hline Rules & 4 & $\begin{array}{l}\text { How often do you restrict the time } \\
\text { your child can use the computer? (Lik-5) }\end{array}$ \\
\hline Biking behavior & 4 & How often do you cycle yourself? (Lik-5) \\
\hline Anthropometry & 6 & $\begin{array}{l}\text { What is your height and weight? } \\
\text { (Open) }\end{array}$ \\
\hline
\end{tabular}

MC-6 Multiple Choice (6 options), Lik-X X-points Likert Scale

children and their route to school. Two trained researchers conducted the environmental scan by walking through the neighborhood. Each scan took about 3-4 h to complete. Environmental attributes that were audited were classified into: 'Schoolyard characteristics' (e.g. play equipment, green spaces, benches), 'Residential buildings' (e.g. numbers of apartment blocks), 'Sports facilities' (e.g. presence of sports fields), 'Playgrounds' (e.g. numbers of playgrounds, equipment at playgrounds, accessibility), 'Parks' (e.g. presence of park, play equipment in park, accessibility), 'Green spaces and water' (e.g. quantity, accessibility), 'Street networks' (e.g. presence of sidewalks, quality of sidewalks), 'Traffic safety in school vicinity' (e.g. presence of busy roads, heavy traffic), 'Street hygiene' (e.g. presence of litter, dog waste), 'Social safety' (presence of hang-outs, dark places), and 'Cyclability and walkability of neighborhood' (general impression of neighborhood). All study areas were revisited after T2 (12 months) to check for environmental changes. In addition, contextual information on the school environment (e.g. residential density) was 'enriched/supplemented' using the Geographic Information System (GIS) (ArcGIS, version 10.2, Top10NL). Furthermore, weather conditions, i.e. temperature, precipitation and hours of sunshine, were obtained for every hour of a measurement day from the Royal Netherlands Meteorological Institute (KNMI).

\section{Procedures of intervention development and implementation}

A combined top-down and bottom-up approach was used to develop and implement tailored, multicomponent school-centered PA interventions (Fig. 1). The 'Active Living' project involved a project team that was composed of a research unit using the top-down approach and a practice unit using the bottom-up approach. Both units were based in the Academic Collaborative Center for Public Health, which facilitated continuous information exchange, leading to ongoing adjustments to the project while in progress. Subsequently, researchers conducted the environmental scans and trained three PHS employees in '(physical/social) environmental thinking', and provided evidence-based PA intervention opportunities. After the start of the project the research unit was involved in monitoring, catalyzing, and evaluating the process, and made adjustments when needed. The trained PHS employees composed a working group at each intervention school consisting of at least the PHS employee as chair, and representatives of the school, parents, and municipal authorities (ideally multidisciplinary, i.e. municipal officials from different disciplines/departments) and was complemented by other stakeholders when possible and necessary. The working groups started with a small budget of 2000 euros each for a period of two school years. Informed by the environmental scan, this working group defined local needs. Based on the needs assessment, an intervention and sustainability plan was formulated, which was assessed by the project team before equipment or training facilities for the interventions were funded. If plans exceeded the budget, additional funding resources were applied for. After (financial) approval by the project team, intervention plans were implemented and monitored for their impact. Meanwhile the bottom-up loop was repeated for additional PA interventions.

\section{Statistical analyses}

PA as measured with accelerometers will be described as activity counts-per-minute (CPM) and by activity levels, i.e. sedentary behavior (SB), light physical activity (LPA), and moderate-to-vigorous physical activity (MVPA). Activity levels will be classified using Evenson's cut-off values [41]. The primary outcome variables for the effectiveness study of Active Living will be the change in CPM $(\triangle \mathrm{CPM})$ and the change in time spent in SB, LPA, and MVPA ( $\Delta$ time spent in SB, LPA and MVPA, respectively) between $\mathrm{T} 1$ and the extended baseline measurement (T0). Differences between T2 and T1 and the extended baseline measurement (T0) will be analyzed to assess the sustainability of the Active Living intervention 
effects. Multivariate multilevel regression analyses will be used to adjust for the nested structure of data in schools. The regression analyses will also be adjusted for age, gender, ethnicity, and weather conditions. Intervention effects of multicomponent physical and social interventions will be studied, as well as their effectiveness under specific conditions, i.e. supportive school environments or home environments. The influence of moderators, such as child characteristics or parental practices, on the intervention effects on children's PA will be studied by including interaction terms of potential moderators in the models. In case of significant moderation, stratified analyses will be used to elucidate conditional factors.

Moreover, we intend to combine objectively (accelerometry and GPS) and subjectively (questionnaires) assessed measures to study the influence of environmental features (observed and perceived), children's characteristics (PA preferences and impulsivity), and parental practices on children's PA. Additional research questions have been formulated, such as 'Do PA preferences predict physical activity?' or 'What is the influence of parental PA practices on children's PA levels?'. The GPS data will allow us to zoom in on certain potentially important environments, such as schoolyards, playgrounds, or routes to school. Due to the limited number of GPS devices (at baseline), these location-specific data will not be part of the effectiveness study, but will be used for additional research questions, such as 'What neighborhood characteristics influence the use of active transportation?'.

\section{Discussion}

The current paper has discussed the development and quasi-experimental evaluation of a school-centered PA intervention. In addition, we have introduced the plan of analysis to investigate the effectiveness of multilevel, multicomponent PA interventions on children's PA, which were developed and implemented using a combined top-down and bottom-up approach. We have also presented an overview of the recruitment procedures and measures, and elaborated on the research questions we will try to answer from our data, in addition to the main study objective.

The Active Living project involved developing and implementing a set of tailored physical and social environmental PA interventions. Every school had a different starting point for this study, and local needs varied greatly, both in focus (active transportation, PA at school, or PA in leisure time) and in content. The effectiveness of the Active Living project will be evaluated as a multilevel (individual, school, and/or neighborhood) multicomponent intervention. In this perspective, we focus on studying the effectiveness of changing the PA-friendliness of the whole school environment to enhance PA, rather than evaluating specific types of interventions. We will report on types of interventions implemented as part of Active Living to create a measure of the magnitude of the total set of physical and social interventions. We believe that studying the tailored development and implementation of a set of interventions in a combined top-down and bottom-up approach is one of the strengths of the Active Living project. Other strengths of the study are our measurements, including both objective assessment methods (accelerometry, GPS, and GIS in combination with environmental scans) and subjective methods (questionnaires among both children and their parents). The objective measurement techniques have already been tested in previous studies using similar target populations [42-44] and enable us to study children's actual physical activity behavior in a broader context, compared to previously used observation tools, such as SOPLAY and OSRAC-H $[45,46]$.

The Active Living study has a quasi-experimental design. RCTs are generally considered to be the gold standard for testing the effectiveness of an intervention [18]. For practical reasons, however, an RCT design seems less appropriate for field studies in which environmental changes are conducted in a wider, less controlled study area, as is the case in the Active Living project. Each of our study areas covers an environmental surface of $2 \mathrm{~km}^{2}$, certain parts of which will not be visited by all participants. Therefore, the exposure to interventions is more difficult to define than in studies focusing on one particular controlled area, such as a schoolyard. Besides, participants are well aware of whether they belong to an intervention school/area, since physical changes are directly visible to participants. Blinding is therefore practically impossible. Furthermore, adaptations in the public municipal domain have to be approved (and co-designed and co-funded) by local authorities and they may be key to the successful implementation of a participatory intervention strategy. Nonetheless, the quasi-experimental research design follows many of the RCT assumptions, and allows us to correct for potential confounding factors, such as sociocultural and political changes to the environment and weather conditions. Moreover, the quasi-experimental study design seems to be suitable for testing the effectiveness of interventions in daily practice, and therefore may facilitate the implementation and continuity of interventions.

\section{Conclusion}

The Active Living project contributes to the knowledge about the relationship between environmental interventions and physical activity. Active Living uses a participatory intervention development strategy, and multicomponent physical and social environmental PA interventions will be 
evaluated for their effects. The outcomes of the Active Living project will guide future projects to design or redesign schools, schoolyards, and their local environment.

\begin{abstract}
Abbreviations
CPM: Counts-per-minute; GIS: Geographic Information System; GPS: Global Positioning System; LPA: Light physical activity; MVPA: Moderate-to-vigorous physical activity; OSRAC-H: Observational System for Recording Physical Activity in Children-Home; PA: Physical activity; PHS: Public Health Service; RCT: Randomized Clinical Trial; SB: Sedentary behavior; SOPLAY: System for Observing Play and Leisure Activity in Youth.
\end{abstract}

\section{Competing interests}

The authors declare that they have no competing interests.

\section{Authors' contributions}

DVK drafted the manuscript and designed the study. MJ, SdV, NdV, and SK helped design the study. MJ initiated the Active Living project and received the project grant. All authors critically reviewed and revised the final version of the manuscript. All authors have read and approved the final manuscript.

\section{Acknowledgements}

We are grateful to all schools and children participating in this study. This study was funded by the Netherlands Organization for Health Research and Development (ZonMw), Project Number 200130003.

\section{Author details}

'Department of Health Promotion, School of Public Health and Primary Care (CAPHRI), Maastricht University, P.O. Box 6166200 MD Maastricht, The Netherlands. ${ }^{2}$ Academic Collaborative Center for Public Health Limburg, Public Health Services, Geleen, The Netherlands. ${ }^{3}$ Department of Health Services Research, School of Public Health and Primary Care (CAPHRI), Maastricht University, P.O. Box 6166200 MD Maastricht, The Netherlands. ${ }^{4}$ TNO, Expertise Center LifeStyle, Leiden, The Netherlands. ${ }^{5}$ The Hague University of Applied Sciences, Research group Healthy Lifestyle in a Supporting Environment, P.O. Box 133362501 EH The Hague, The Netherlands. ${ }^{6}$ Department of Health Promotion, Nutrition and Translational Research Institute Maastricht (NUTRIM), Maastricht University, P.O. Box 616 6200 MD Maastricht, The Netherlands.

\section{Received: 27 October 2015 Accepted: 16 December 2015}

\section{Published online: 29 December 2015}

\section{References}

1. Lobstein T, Jackson-Leach R, Moodie ML, Hall KD, Gortmaker SL, Swinburn BA, et al. Child and adolescent obesity: part of a bigger picture. Lancet. 2015:385(9986):2510-20.

2. Lobstein T, Baur L, Uauy R. Obesity in children and young people: a crisis in public health. Obes Rev. 2004:5:4-85.

3. Schönbeck Y, Talma H, van Dommelen P, Bakker B, Buitendijk SE, HiraSing RA, et al. Increase in Prevalence of Overweight in Dutch Children and Adolescents: A Comparison of Nationwide Growth Studies in 1980, 1997 and 2009. PLoS ONE. 2011;6(11):e27608.

4. Brennan LK, Brownson RC, Orleans CT. Childhood Obesity Policy Research and Practice: Evidence for Policy and Environmental Strategies. Am J Prev Med. 2014;46(1):e1-e16.

5. Ahrens W, Pigeot I, Pohlabeln H, De Henauw S, Lissner L, Molnar D, et al. Prevalence of overweight and obesity in European children below the age of 10. Int J Obes. 2014:38(S2):S99-S107.

6. Parsons TJ, Power C, Logan S, Summerbell CD. Childhood predictors of adult obesity: a systematic review. Int J Obes Relat Metab Disord. 1999; 23(S8):S1-107.

7. Singh AS, Mulder C, Twisk JW, van Mechelen W, Chinapaw MJ. Tracking of childhood overweight into adulthood: a systematic review of the literature. Obes Rev. 2008;9(5):474-88.

8. Kohl HW, Craig CL, Lambert EV, Inoue S, Alkandari JR, Leetongin G, et al. The pandemic of physical inactivity: global action for public health. Lancet. 2012;380(9838):294-305.

9. Mitchell JA, Pate RR, Beets MW, Nader PR. Time spent in sedentary behavior and changes in childhood BMl: a longitudinal study from ages 9 to 15 years. Int J Obes. 2013;37(1):54-60.
10. Pearson N, Braithwaite RE, Biddle SJH, van Sluijs EMF, Atkin AJ. Associations between sedentary behaviour and physical activity in children and adolescents: a meta-analysis. Obes Rev. 2014;15(8):666-75.

11. Saunders TJ, Chaput J-P. Tremblay MS. Sedentary Behaviour as an Emerging Risk Factor for Cardiometabolic Diseases in Children and Youth. Can J Diabetes. 2014;38(1):53-61.

12. Andersen L, Harro M, Sardinha L, Froberg K, Ekelund U, Brage S, et al. Physical activity and clustered cardiovascular risk in children: A cross-sectional study (The European Youth Heart Study). Lancet. 2006;368:299-304.

13. Biddle SJH, Gorely T, Stensel DJ. Health-enhancing physical activity and sedentary behaviour in children and adolescents. J Sports Sci. 2004;22(8):679-701.

14. Fedewa AL, Ahn S. The Effects of Physical Activity and Physical Fitness on Children's Achievement and Cognitive Outcomes. Res Quart Exerc Sport. 2011:82(3):521-35

15. Panter J, Jones A, van Sluijs E. Environmental determinants of active travel in youth: A review and framework for future research. Int J Behav Nutr Phys Act. 2008;5(1):34

16. Hume C, Timperio A, Salmon J, Carver A, Giles-Corti B, Crawford D. Walking and Cycling to School: Predictors of Increases Among Children and Adolescents. Am J Prev Med. 2009;36(3):195-200.

17. Rush E, Simmons D. Physical Activity in Children: Prevention of Obesity and Type 2 Diabetes. In: Goedecke JH, Ojuka EO, editors. Diabetes and Physical Activity. Volume 60. Basel: Med Sport Sci, Karger; 2014. p. 113-21.

18. Dobbins M, Husson H, DeCorby K, LaRocca R. School-based physical activity programs for promoting physical activity and fitness in children and adolescents aged 6 to 18. Cochrane Database Syst Rev. 2013;2.

19. Kriemler S, Meyer U, Martin E, van Sluijs E, Andersen L, Martin B. Effect of school-based interventions on physical activity and fitness in children and adolescents: a review of reviews and systematic update. Br J Sports Med. 2011:45:923-30.

20. Story M, Nanney M, Schwartz M. Schools and obesity prevention: creating school environments and policies to promote healthy eating and physical activity. Milbank Q. 2009:87:71-100.

21. Koplan JP, Liverman CT, Kraak VI. Preventing childhood obesity: Health in the balance: Executive summary. J Am Diet Assoc. 2005;105(1):131-8.

22. Pate RR, Davis MG, Robinson TN, Stone EJ, McKenzie TL, Young JC. Promoting Physical Activity in Children and Youth: A Leadership Role for Schools: A Scientific Statement From the American Heart Association Council on Nutrition, Physical Activity, and Metabolism (Physical Activity Committee) in Collaboration With the Councils on Cardiovascular Disease in the Young and Cardiovascular Nursing. Circulation. 2006:114(11):1214-24

23. Broekhuizen $\mathrm{K}$, Scholten A-M, de Vries S. The value of (pre)school playgrounds for children's physical activity level: a systematic review. Int J Behav Nutr Phys Act. 2014;11(1):59.

24. Escalante Y, García-Hermoso A, Backx K, Saavedra JM. Playground Designs to Increase Physical Activity Levels During School Recess: A Systematic Review Health Educ Behav. 2014:41(2):138-44.

25. Ridgers N, Salmon J, Parrish A, Stanley R, Okely A. Physical activity during school recess: a systematic review. Am J Prev Med. 2012:43(3):320-8.

26. Parrish A, Okely A, Stanley R, Ridgers N. The effect of school recess interventions on physical activity: a systematic review. Sports Med. 2013:43:287-99.

27. Sallis JF, Cervero RB, Ascher W, Henderson KA, Kraft MK, Kerr J. An Ecological Approach to Creating Active Living Communities. Annu Rev Public Health. 2006:27:297-322

28. Gubbels J, Van Kann D, de Vries N, Thijs C, Kremers S. The next step in health behavior research: the need for ecological moderation analyses - an application to diet and physical activity at childcare. Int J Behav Nutr Phys Act. 2014;11(1):52

29. Swinburn B, Egger G, Raza F. Dissecting obesogenic environments: the development and application of a framework for identifying and prioritizing environmental interventions for obesity. Prev Med. 1999:29(6 Pt 1):563-70.

30. Knol F. Statusontwikkeling van wijken in Nederland 1998-2010 [Status development of neighborhoods in the Netherlands 1998-2010]. The Hague: The Netherlands Institute for Social Research (SCP); 2012

31. De Vries SI, Chorus AMJ. Bewegen in Nederland: jeugdigen van 4-17 jaar (Physical activity in the Netherlands: youngsters aged 4-17 years). In: Hildebrandt VH, Chorus AMJ, Stubbe JH, editors. TNO Trendrapport Bewegen en Gezondheid. Leiden: De Bink; 2010. p. 57-76. 
32. Ooijendijk W, Wendel-Vos W, de Vries S. Consensus Vragenlijsten Sport en Bewegen [Consensus Questionnaires on Sports and Physical Activity]. Leiden: TNO; 2007.

33. Timperio A, Crawford D, Telford A, Salmon J. Perceptions about the local neighborhood and walking and cycling among children. Prev Med. 2004;38(1):39-47.

34. Rodenburg G, Oenema A, Pasma M, Kremers SPJ, van de Mheen D. Clustering of food and activity preferences in primary school children. Appetite. 2013;60:123-32

35. Sleddens EF, Kremers SP, de Vries NK, Thijs C. Measuring child temperament: Validation of a 3-item Temperament Measure and 13-item Impulsivity Scale. Eur J Develop Psych. 2013;10(3):392-401.

36. Timperio A, Ball K, Salmon J, Roberts R, Giles-Corti B, Simmons D, et al. Personal, family, social, and environmental correlates of active commuting to school. Am J Prev Med. 2006:30(1):45-51.

37. Davison KK, Li K, Baskin ML, Cox T, Affuso O. Measuring parental support for children's physical activity in white and African American parents: The Activity Support Scale for Multiple Groups (ACTS-MG). Prev Med. 2011;52(1):39-43

38. De Vries SI, Hopman-Rock M, Bakker I, Hirasing RA, Van Mechelen W. Built Environmental Correlates of Walking and Cycling in Dutch Urban Children: Results from the SPACE Study. Int J Environ Res Public Health. 2010; $7(5): 2309-24$

39. Saelens B, Sallis J, Frank L. Environmental correlates of walking and cycling: Findings from the transportation, urban design, and planning literatures. Ann Behav Med. 2003;25(2):80-91.

40. Centraal Bureau voor de Statistiek (CBS). Statline: Nabijheid voorzieningen; afstand locatie, wijk- en buurtcijfers 2013. Voorburg/Heerlen: CBS; 2014.

41. Evenson K, Catellier D, Gill K, Ondrak K, McMurray R. Calibration of two objective measures of physical activity for children. J Sports Sci. 2008;26(14):1557-65

42. Dessing D, Pierik F, Sterkenburg R, van D, Maas J, De Vries S. Schoolyard physical activity of 6-11 year old children assessed by GPS and accelerometry. Int J Behav Nutr Phys Act. 2013;10:97.

43. Klinker C, Schipperijn J, Christian H, Kerr J, Ersboll A, Troelsen J. Using accelerometers and global positioning system devices to assess gender and age differences in children's school, transport, leisure and home based physical activity. Int J Behav Nutr Phys Act. 2014;11(1):8.

44. Klinker CD, Schipperijn J, Kerr J, Ersbø\|l AK, Troelsen J. Context-specific outdoor time and physical activity among school-children across gender and age: Using accelerometers and GPS to advance methods. Front Public Health. 2014;2:20

45. McKenzie T, Marshall S, Sallis J, Conway T. Leisure-time physical activity in school environments: an observational study using SOPLAY. Prev Med. 2000;30:70-7.

46. Mclver KL, Brown WH, Pfeiffer KA, Dowda M, Pate RR. Assessing Children's Physical Activity in Their Homes: The Observational System for Recording Physical Activity in Children-Home. J Appl Behav Anal. 2009:42(1):1-16.

\section{Submit your next manuscript to BioMed Central and we will help you at every step:}

- We accept pre-submission inquiries

- Our selector tool helps you to find the most relevant journal

- We provide round the clock customer support

- Convenient online submission

- Thorough peer review

- Inclusion in PubMed and all major indexing services

- Maximum visibility for your research

Submit your manuscript at www biomedcentral.com/submit

) Biomed Central 